\title{
Review Article \\ Comprehensive Study on the Acrylamide Content of High Thermally Processed Foods
}

\author{
Dilini N. Perera $(\mathbb{D}$, Geeth G. Hewavitharana $(\mathbb{D}$, and S. B. Navaratne \\ Department of Food Science and Technology, University of Sri Jayewardenepura, Nugegoda 10250, Sri Lanka \\ Correspondence should be addressed to Geeth G. Hewavitharana; gayeshageeth@gmail.com
}

Received 9 July 2020; Revised 10 February 2021; Accepted 13 February 2021; Published 23 February 2021

Academic Editor: Tanveer A. Wani

Copyright @ 2021 Dilini N. Perera et al. This is an open access article distributed under the Creative Commons Attribution License, which permits unrestricted use, distribution, and reproduction in any medium, provided the original work is properly cited.

\begin{abstract}
Acrylamide (AA) formation in starch-based processed foods at elevated temperatures is a serious health issue as it is a toxic and carcinogenic substance. However, the formation of more AA entangles with modern-day fast food industries, and a considerable amount of this ingredient is being consumed by fast food eaters inadvertently throughout the world. This article reviews the factors responsible for AA formation pathways, investigation techniques of AA, toxicity, and health-related issues followed by mitigation methods that have been studied in the past few decades comprehensively. Predominantly, AA and hydroxymethylfurfural (HMF) are produced via the Maillard reaction and can be highlighted as the major heat-induced toxins formulated in bread and bakery products. Epidemiological studies have shown that there is a strong relationship between AA accumulation in the body and the increased risk of cancers. The scientific community is still in a dearth of technology in producing AA-free starch-protein-fat-based thermally processed food products. Therefore, this paper may facilitate the food scientists to their endeavor in developing mitigation techniques pertaining to the formation of AA and HMF in baked foods in the future.
\end{abstract}

\section{Introduction}

Food processing generally includes the basic preparation that is used to convert raw ingredients into food or food into other forms of consumption. Numerous processing stages such as washing, cutting, drying, frying, fermenting, cooking, and many more are involved as a single operation or a combination. During these processing steps, some toxic compounds can be formed [1]. AA is one among such heatinduced toxic substance which may be developed in starchy foods at high-temperature processing primly via the Milliard reaction pathway [2]. It can be formed in baked, fried, grilled, toasted, and roasted foods $[3,4]$.

AA $\left(\mathrm{C}_{3} \mathrm{H}_{5} \mathrm{NO}\right.$; prop-2-enamide) is a colorless, odorless, and water-soluble compound and thermally decomposes to $\mathrm{CO}_{2}, \mathrm{CO}, \mathrm{NO}_{2}$, and $\mathrm{NH}_{3}$ [5]. In 2002, the Swedish National Food Authority and Stockholm University have discovered that $\mathrm{AA}$ in foods was processed above the temperature of $120^{\circ} \mathrm{C}$ [6]. Based on its toxicity, different tolerable daily intakes were estimated. To avoid AA neurotoxicity, intake is estimated at $40 \mu \mathrm{g} / \mathrm{kg}$ bw/day, and to avoid its carcinogenic effects, $2.6 \mu \mathrm{g} / \mathrm{kg}$ bw/day $[7,8]$. Different factors can be investigated with respect to the formation of AA in foods, and consequently, formation mechanisms, several mitigation approaches, and future perspectives were discussed in this review.

\section{Factors Affecting Acrylamide Formation}

Food composition and processing conditions are the two main factors that directly affect AA formation. Food composition includes the availability of amino acids, presence of sugars, $\mathrm{pH}$, and moisture of the food [9]. Reducing sugar and amino acids are the starting reactants. Asparagine is the key amino acid, and the presence of mono or disaccharides such as glucose, fructose, and sucrose directly affects the formation of AA [10]. The reactivity of sugars differs according to their chain length; sugars that have shorter carbon chains lead to high AA formation. Thus, pentoses are more reactive than hexoses and disaccharides in yielding brown color in the Maillard reaction [11, 12]. Also, aldo sugars are more reactive than keto sugars, and among 
isomeric sugars, ribose is more reactive than xylose in AA formation $[13,14]$.

When comparing the availability of reducing sugars and amino acids for AA formation in potatoes, cereal products, and coffee, some limiting factors for the reaction can be found. Asparagine and glutamine are abundant in potatoes and lack in reducing sugars [15]. For cereal products, asparagine is limited [16], and coffee is rich in both asparagine and sucrose, which during roasting sucrose fragmented into glucose and fructose [17]. Then, AA was formed in those food products. Water content in the food matrix can also affect AA formation. Water activity would be below 0.8 which facilitates the formation of AA, whereas the AA formation is high at the water activity 0.4 or below [8]. However, AA can be removed from heated foods such as biscuits and potato chips with an increase in water activity [18]. Anese et al. [19] reported that $32 \%$ of acrylamide can be removed in cookies at water activity 0.83 , whereas it is $12 \%$ at water activity 0.12 . In potato chips, acrylamide removal zeroes at the water activity 0.26 while it is $20 \%$ at water activity 0.95 .

The $\mathrm{pH}$ of the medium is another factor that is strongly influenced by the Maillard reaction and then leads to AA formation. Acidic conditions disrupt the AA formation, thus lowering the $\mathrm{pH}$ using organic acids in the food system which resulted in reduced acrylamide generation by protonating the $\alpha$-amino group of asparagine, which subsequently cannot engage in nucleophilic addition reactions with carbonyl sources. The correlation between $\mathrm{pH}$ decrease and acrylamide reduction varies among products due to multiple factors of different starting $\mathrm{pH}$ values of the products [20].

Since AA formation is initiated by heat, the effect of processing temperature and time in relation to AA formation is critically important. According to the Arrhenius equation, temperature dependence of chemical reactions is often expressed as the activation energy (Ea) [21]. The higher the $\mathrm{Ea}$, the more temperature-dependent the reaction rate. The Ea for the Maillard reaction which is directly proportional to AA formation has been reported within a wide range, $10-160 \mathrm{~kJ} \mathrm{~mol}^{-1}[22]$, depending on other factors that affect the reaction has been measured. Matthäus et al. [23] reported that time duration is a key factor especially frying temperature at or above $175^{\circ} \mathrm{C}$. They reported a rapid increase in AA concentration at $180-190^{\circ} \mathrm{C}$ compared to lower temperatures $\left(150^{\circ} \mathrm{C}\right.$ and $\left.175^{\circ} \mathrm{C}\right)$.

\section{Formation of Acrylamide}

AA is not a component of food; it is formed during heat processing. The reaction routes for the formation of AA during processing can be explained based on different hypotheses that were found to be most relevant and probable in a processing situation. The main precursors reported for AA formation included 3-aminopropionamide (3APA), decarboxylated Schiff base, decarboxylated Amadori product, acrylic acid, and acrolein [4, 20, 23]. According to the literature, there are two most accepted pathways; the Maillard reaction pathway and the acrolein pathway [8] which were explained in the following section.
The formation of AA via the Maillard reaction is known as the major pathway; the reaction between free amino acids such as asparagine and reducing sugars generates a Schiff base by the removal of water from sugar-protein conjugate, and further decarboxylates through the formation of oxazolidine-5-one. The decarboxylated product decays to AA through the removal of imine or after hydrolyzation to form 3-APA [24] (Figure 1). Zhang et al. [25] reported that this asparagine pathway was mainly accountable for AA formation in cooked foods' subsequent condensation with reducing sugars. In model studies, it has been shown that $\alpha$-hydroxy carbonyls are more efficient than $\alpha$-dicarbonyls in forming AA [26]. Furthermore, Eriksson [27] reported that fructose increases the AA content by about two times in comparison with other reducing sugars because it contains two $\alpha$-hydroxylic groups rather than one as is the case with other sugars such as glucose.

Besides, 3-APA can be formed AA in the absence of reducing sugars. Based on structural considerations, asparagine alone can be changed into AA through decarboxylation and deamination reactions under thermal processing $[27,28]$. Nevertheless, the key product of thermal degradation of asparagine is maleimide; however, it prevents the formation of AA due to rapid intramolecular cyclization reactions [29].

Apart from the major pathway, the Strecker reaction of asparagine generates direct intermediate as Strecker aldehydes [31] (Figure 2). Mottram et al. [32] reported that AA was formed during heat processing associated with amino acids and reducing sugars; hence, most of the flavors and color generated from intermediates have formed the Strecker degradation of amino acids during baking and roasting.

The acrolein pathway is the second most accepted way of AA formation. AA is generated from oil when heated at temperatures above the smoke point. Initially, oil is hydrolyzed into glycerol and fatty acids followed by the elimination of water from glycerol and produced acrolein via heterolytic acid-catalyzed carbonium ion mechanism [33, 34] (Figure 3). Oils, which are highly unsaturated and have a lower smoke point, lead to the formation of acrolein [35].

There are some other possible ways of acrolein formation such as degradation of amino acids and proteins, degradation of carbohydrates, and decarboxylation of an organic acid such as lactic acid, citric acid, and malic acid [33] (Figure 4), hence resulting in acrolein which further reacts with $\mathrm{NH}_{3}$ to produce AA, but it is limited to some extent because carbonyl compounds such as reducing sugars are more active with asparagine than them [4].

3.1. Determination of Acrylamide. Analytical methods are mainly based on the mass spectrometry (MS) technique coupled with either liquid chromatography (LC) or gas chromatography (GC) [36]. Wenzl et al. [37] have reported that the performance of the LC method was greater than the GC method. Since AA is a tiny, extremely polar molecule, its extraction and analysis are difficult. Sample preparation had a great influence on the accurate quantification of AA. Since AA may be firmly enclosed and concentrated at the surface, the whole food sample should be homogenized thoroughly 


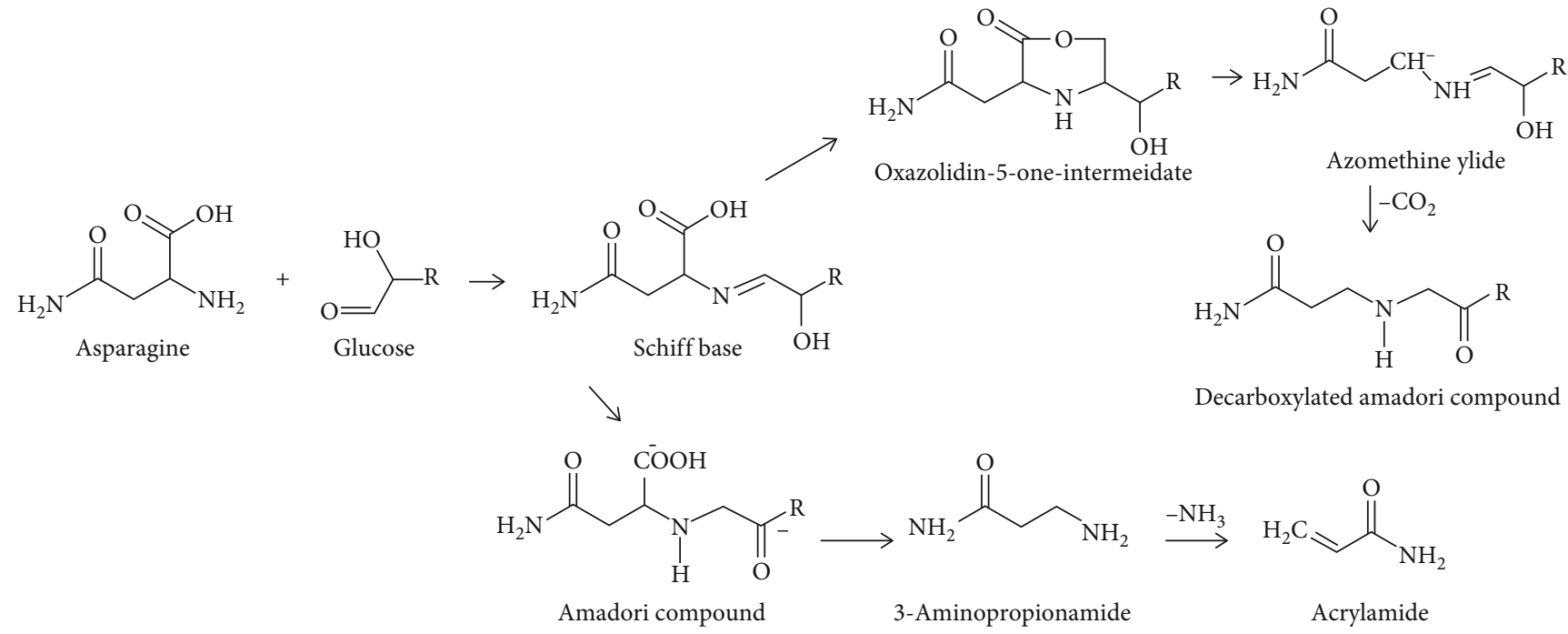

FIgURE 1: The major pathway for AA formation in food [30].

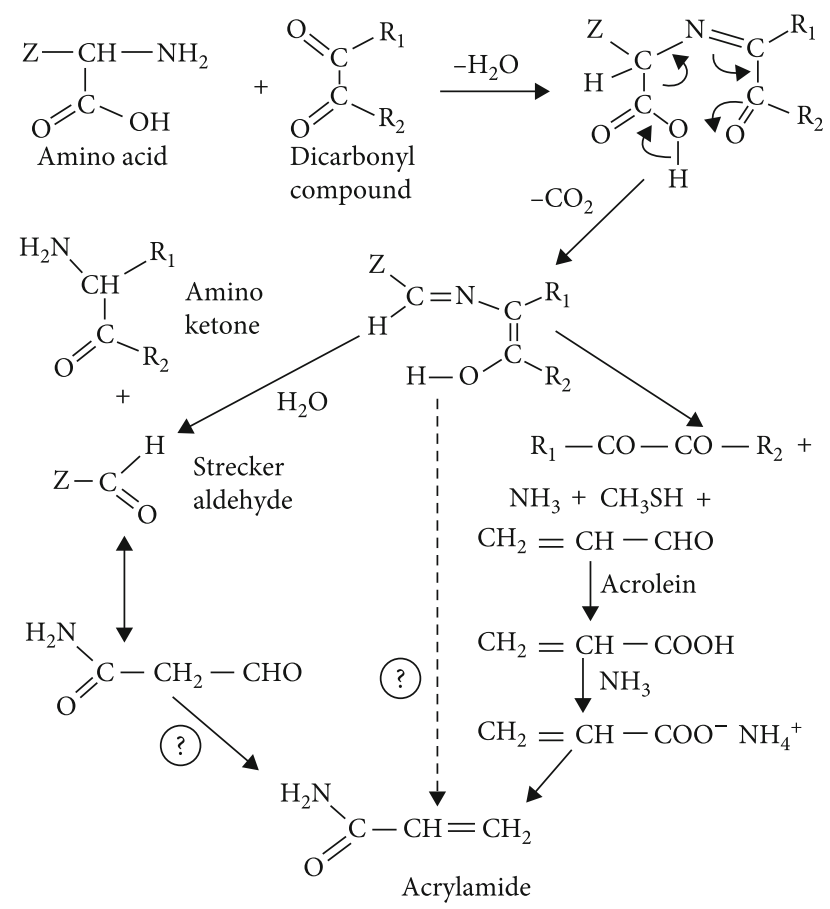

Figure 2: Pathways for the formation of AA after Strecker degradation of amino acids asparagine and methionine. In asparagine, the side chain $\mathrm{Z}$ is $-\mathrm{CH}_{2} \mathrm{CONH}_{2}$; in methionine, it is $\mathrm{CH}_{2} \mathrm{CH}_{2} \mathrm{SCH}_{3}$ [26].

before a sample is taken for analysis. Thereafter, internal standard (IS), defatting, extraction, concentration, and cleanup (in some methods also derivatization) were added, and chromatography/detection were followed [37-39]. AA quantification can be done based on the external and internal standard method. An IS should be added to the extraction, to overcome the poor reproducibility and recovery yield of AA. Thus, it improves the accuracy and precision and reduces the quantitative issues associated with ion suppression [38].
Figure 5 illustrates the basic flow chart of sample preparation for GC-MS analysis.

There is no fully accepted extraction method of AA from various food. AA is readily soluble in water, lower alcohols, and other polar organic solvents [40]. Extraction can be done with water or with an organic solvent. The water reduces the solubility of hydrophobic compounds and also minimizes the extraction of other unwanted compounds such as salts, proteins, and carbohydrates, which might interfere with the detection and degenerate the chromatographic system in the food products. Starch, protein, and fat should be removed after extraction with water $[41,42]$. Consequently, defatting must be done using organic solvents such as hexane, dichloromethane, petroleum ether, and cyclohexane, because highfat content leads to overlapping peaks of AA or disruptive the analytical column of GC [36]. For high-protein samples, deproteinization can be done with acetonitrile (ACN), methanol, ethanol, acetone, sodium chloride, or Carrez reagents, and filtration through a cutoff filter $[12,40]$. Furthermore, to achieve a better penetration of the solvents, elevated temperatures are used for swelling of the food matrix [43]. Apart from water, organic solvents such as n-propanol, methanol, acetone, and ACN can also be used for AA extraction [36]. Organic solvents give clear solution mostly without centrifugation, and it extracts lipids and can be evaporated easily.

Moreover, a quick and automated solvent extraction method with pure water and formic acid was introduced by Cavalli et al. [44]. They reported that pure water extracts exhibited lower recoveries than the formic acid, but the formic acid extracts had lowered the stability. Extraction can be completed by single-stage or a combination of stages. Single-stage extraction has been substantially applied to extract AA from compact food matrices using slight variations in extraction conditions [43]; extraction solvent type, solvent-to-sample ratio, extraction time, temperature, particle size, defatting, homogenization, and the application of mechanical forces affect AA extraction yield [42, 44]. AA also can extract through the salt-out technique from the aqueous mixture and concentrated through rotary evaporation. In 


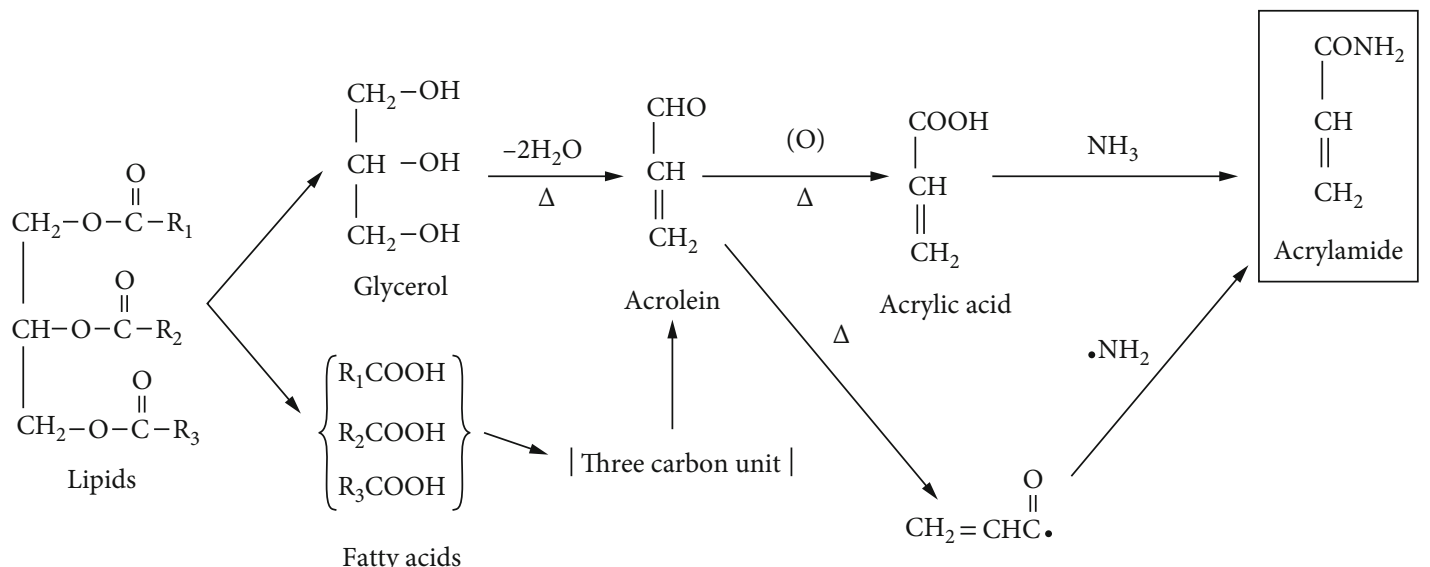

FIgURE 3: Acrolein pathway for AA formation in foods [8].
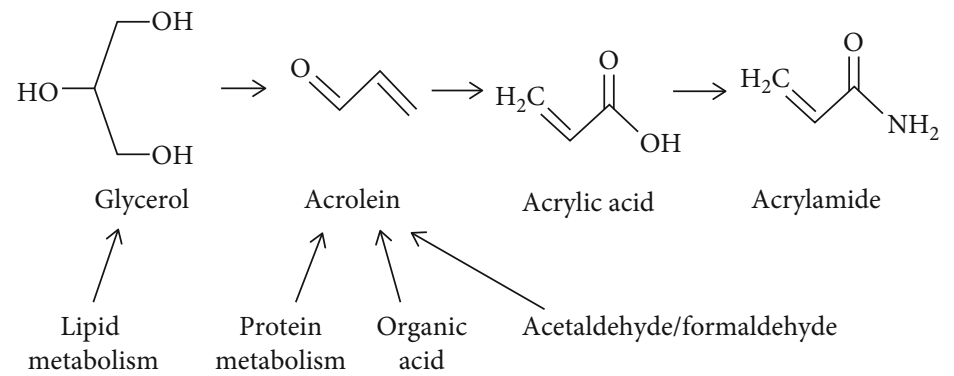

Figure 4: Possible ways of acrolein formation [30].

this method, ethyl acetate (EtAc) was used as it prevents the extraction of other interfering substances which include salt, sugars, starches, and amino acids [45].

Apart from conventional methods, novel sample preparation methods are also used for the analysis. The dispersive solid-phase extraction (DSPE) method leads to rapid, easy, economical, and safe extractions [45]. Matrix solid-phase dispersion (MSPD) offers a porous structure that the solvent can penetrate easily [46]. Pressurized fluid extraction (PFE) comprises extraction with liquid solvents at higher temperatures and pressures which have already been used for the extraction of AA from foods [47]. Other than that, solventfree sample preparation techniques such as solid-phase microextraction (SPME) can be used in the analysis of AA [48]. In this method, the extrication of analytes from the sample followed by fiber coating and then desorption of the extract from the fiber into the analytical instrument where the sample components are thermally desorbed generally in GC were performed $[36,49]$. Furthermore, the AA could be extracted either by directly submerging the solid phase in an aqueous solution (DISPME) or submerging the vapor phase above the aqueous solution, known as headspace (HS-SPME) [50].

Derivatization is done to reduce the polarity of AA, expand the retention time, regulate peaks, and ensure the optimization of corresponding parameters [51]. The GCMS analysis based on bromination has advantages such as bromination produces fewer polar molecules than the natural AA, which is easily extracted by EtAc or hexane, and elim- inating many water-soluble components enlarges AA molecular weight, which leads to improved mass spectrometry (MS) characteristics, giving several ions to monitor and confirm, and relatively more volatile derivatization product improves GC characteristics [52]. Commonly, a bromine water solution with $\mathrm{HBr}$ and $\mathrm{KBr}$ or a mixture of $\mathrm{KBr}$ and $\mathrm{KBrO}_{3}$ is added into the pretreated AA extracts. Tables 1 and 2 indicate a summary of reported AA extraction and derivatization methods and AA content in different food varieties respectively.

Bromination is carried out at a refrigerator or on ice in a dark place [36]. Methacrylamide or N,N-dimethylacrylamide could be used as IS produce a derivative of 2,3-dibromo-2methylpropionamide. Thus, the end derivative 2,3-dibromopropionamide is rather unstable and might degrade in the GC injector to 2bromopropenamide [53]. After the derivatization, the excess bromine is removed by titration with sodium thiosulfate $\left(\mathrm{Na}_{2} \mathrm{~S}_{2} \mathrm{O}_{3}\right)$. The brominated AA is less polar compared with the extracted compound, which is more soluble in nonpolar organic solvents [54]. Frequently, EtAc or a combination of EtAc and cyclohexane is used for the extraction of the analyte from the aqueous phase [39]. Phase separation is frequently conducted by centrifugation of the sample. Moreover, cleanup was carried out by passing organic extract through a silica-gel cartridge [26]. Due to the high-water absorptivity of silica, EtAc must be dried or exchanged with cyclohexane to avoid variations of the silica activity. Current studies reported that the remaining water and water-soluble coextractant will interfere with the results 


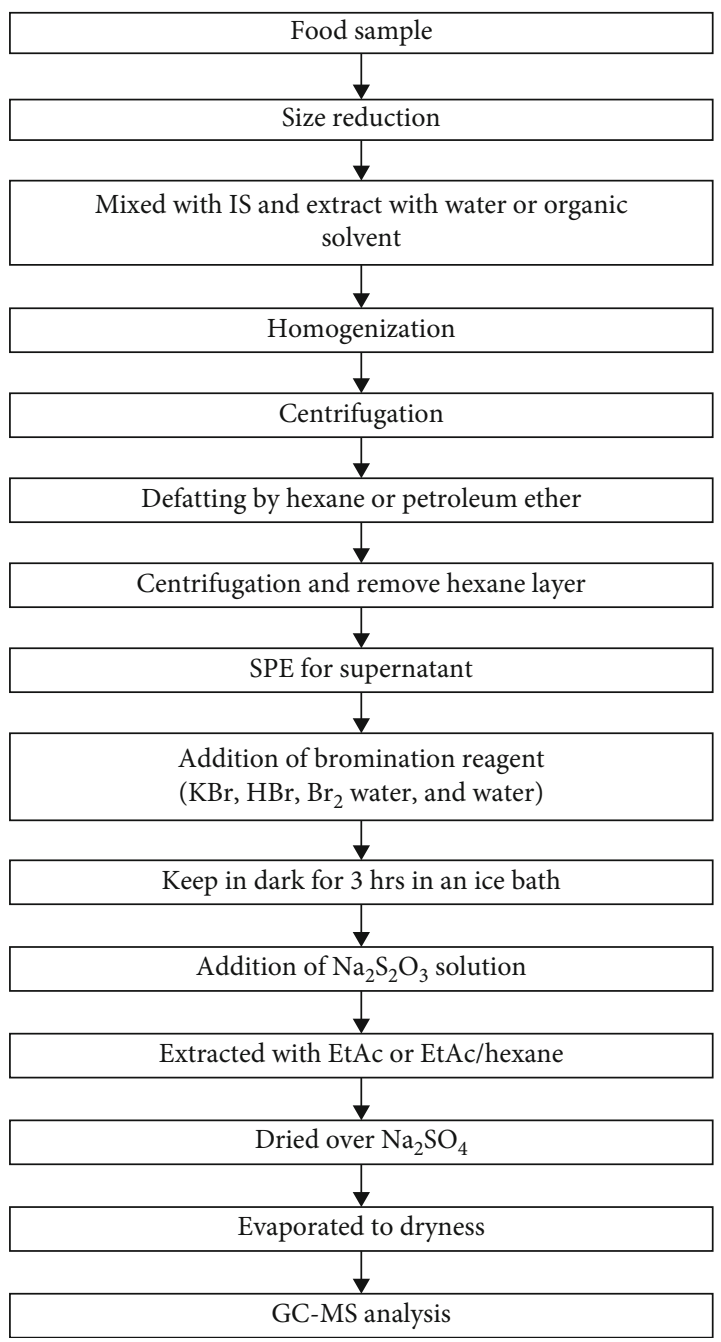

FIGURE 5: Sample preparation flow chart.

and can be eliminated by drying the extract $\mathrm{Na}_{2} \mathrm{SO}_{4}$ [36]. Generally, midpolar to polar columns are used for bromo derivatives in GC analysis [4]. Apart from the bromination of AA, other techniques such as HS-SPME can be done by silylation with $\mathrm{N}, \mathrm{O}$-bis(trimethylsilyl) trifluoroacetamide (BSTFA) to form the volatile N,O-bis(trimethylsilyl) acrylamide (BTMSA) [36]. Then, the generated BTMSA is extracted over the silylation reaction with the use of a poly(dimethylsiloxane) SPME fiber from the headspace [54].

\section{Toxicity of Acrylamides}

Scientists have focused on the different health effects of AA due to its high toxicity. It could be inducing neurotoxicity, genotoxicity, carcinogenicity, hepatotoxicity, and reproductive toxicity to humans and animals $[74,75]$. AA and its toxicity have been evaluated by the International Agency for Research on Cancer (IARC) and by the Joint FAO/WHO Expert Committee on Food Additive (WHO/JECFA) [76, 77]. According to their findings, average human intake is valued to be $0.4 \mu \mathrm{g} / \mathrm{kg}$ bw/day from two years of age, though consumption may vary generally from $0.3 \mu \mathrm{g} / \mathrm{kg}$ bw/day to $5 \mu \mathrm{g} / \mathrm{kg}$ bw/day. The estimate of average daily human intake was $1 \mu \mathrm{g} / \mathrm{kg}$ bw/day, and it can be $4 \mu \mathrm{g} / \mathrm{kg}$ bw/day for high consumers [77]. Several toxic effects of AA are summarized in the following section.

AA is a neurotoxicant, which can be accidental intoxications or chronic occupational exposure, and affected central nervous system (CNS) and peripheral nervous system (PNS) in rodents and humans [78]. The toxic effect depends on exposure time and dosage. Highly exposed workers in china were shown to that peripheral neuropathy symptom such as skeletal muscle weakness, tingling of hands and feet, and ataxia. Thus, cerebellar Purkinje cells and distal axons in the central nervous system were also affected [79]. Furthermore, the degradation of nerve terminals which act as a primary site of AA action leads to the weakening of cognitive functions and damage to the cerebral cortex, thalamus, and hippocampus [80]. According to the studies in rats and mice, NOEL (no observable effect level) for neurotoxicity was reported as 0.2 to $10 \mathrm{mg} / \mathrm{kg}$ bw/day [81].

AA is a directly acting clastogen, which causes abnormality in genes that leads to genotoxicity. In mammalian cells, metabolic conversion of AA into glycidamide (GA) causes mutagenic effects at the HPRT locus, and also, AA can act as a Michael acceptor and form adducts with thiol, hydroxyl, or amino groups and nucleophilic centers in DNA. AA also induces germ cell mutations $[29,82]$. It was recently found that GA significantly induces micronuclei, impairs cell propagation kinetics, and decreases cell viability at high concentrations by mechanisms not involving oxidative stress. Further, it is confirming that human mammary cells are susceptible to GA toxicity $[83,84]$.

In 1994, the IARC had been classified AA as possible carcinogenic to humans based on the positive bioassay results in rodents and other evidence by the genotoxic effect of GA [77, 85]. Formation of covalent adducts with DNA and hemoglobin, induction of chromosomal aberrations in somatic cells of rodents in vivo, chromatic mutations, and chromosomal abnormalities in cultured and germ cells in vitro, and induction of cell transformation in mouse cell lines indicated the carcinogenic effect [30]. Important laboratory experiments of rodents illustrated that AA is carcinogenic, causing tumors in the lungs, skin, brain, mammary gland, thyroid gland, and uterus $[81,85]$. Occupational exposure to AA seems to be the most affected to human cancer risk.

The reproductive and developmental toxicity of AA has been demonstrated with laboratory animals. No observed adverse effect level was reported as 2 to $5 \mathrm{mg} / \mathrm{kg} /$ day in rats [86]. After injection of exogenous AA to rodents, disturbing mating, reduced fertility rates, increased resorptions of fetuses, reduced litter size in pregnant females, abnormal sperm, and low sperm count in males were shown [87]. These effects are associated with gene mutilation, alkylation of sulfhydryl (SH) groups, reduction of glutathione (GSH), and DNA damages [88]. However, there was less evidence for the potential effects of reproductive and developmental toxicity for humans.

Some researchers have discussed the hepatotoxicity effect of AA due to oxidative stress. Based on the experimental 
TABLE 1: Summary of reported AA extraction and derivatization methods in different food products.

\begin{tabular}{|c|c|c|}
\hline Food sample & Extraction and analysis method & Reference \\
\hline \multirow[b]{2}{*}{ French fries } & $\begin{array}{l}\text { Extraction with water and subjected to solid-phase extraction (SPE). Derivatization with brominating reagent } \\
\qquad(\mathrm{KBr}, \mathrm{HBr} \text {, and } \mathrm{Br} 2 \text { water) }\end{array}$ & {$[55]$} \\
\hline & $\begin{array}{l}\text { Extraction with water and 1,2-dichloroethane } \\
\text { Derivatization with xanthydrol solution and } 1 \mathrm{~mL} \text { of } \mathrm{HCl} \text { at } 40^{\circ} \mathrm{C} \text { in the dark, then slightly alkalinized with } \\
\mathrm{KOH} \text { and followed by saturated } \mathrm{NaCl} \text {. Then, } \mathrm{AA} \text { derivative was extracted twice with EtAc. }\end{array}$ & {$[56]$} \\
\hline & Extracted with water and derivatized with the brominating reagent & {$[57]$} \\
\hline Bakery products & $\begin{array}{l}\text { Extracted with water-methanol }(80: 20) \\
\text { Derivatization with xanthydrol and } 1 \mathrm{~mL} \mathrm{HCl} \text { at } 40^{\circ} \mathrm{C} \text { in the dark } \\
\text { AA derivative was extracted with ethylene tetrachloride and methanol. Then directly injected into the GC- } \\
\text { MS. }\end{array}$ & {$[58]$} \\
\hline \multirow[t]{2}{*}{ Cereals } & $\begin{array}{c}\text { The sample was mixed with water and shaken to get a soft dough. IS and } \mathrm{KOH} \text { : ethanol }(80: 20) \text { was added } \\
\text { and centrifuged followed by the upper clear aqueous phase was separated. } \\
\text { Derivatization with xanthydrol and } 1 \mathrm{~mL} \mathrm{HCl} \text { at } 40^{\circ} \mathrm{C} \text { in the dark. AA derivative was extracted using } \\
\text { Dispersive liquid-liquid microextraction with tetrachloroethylene as extracting solvent and ethanol as a } \\
\text { dispersing solvent, then directly injected into the GC-MS. }\end{array}$ & {$[59]$} \\
\hline & $\begin{array}{l}\text { The sample was spiked with IS and added distilled water, homogenized, and acidified to } \mathrm{pH} 4-5 \text { by glacial } \\
\text { acetic acid, and Carrez reagent was added, then centrifuged, and the supernatant was filtered, derivatized with } \\
\text { calcinated } \mathrm{KBr}, \mathrm{HBr} \text {, and saturated } \mathrm{Br}_{2} .\end{array}$ & {$[60]$} \\
\hline Coffee & $\begin{array}{l}\text { Extraction was done by using MSPD. } \\
\text { Derivatization with the brominating reagent }\end{array}$ & {$[61]$} \\
\hline Baby foods & $\begin{array}{l}\text { The sample was defatted with } \mathrm{n} \text {-hexane and vortexed. The supernatant was removed by filtration. Then, the } \\
\text { solid was dried and spiked with IS, and the aqueous layer was filtered through a syringe filter. } \\
\text { Derivatized with the brominating reagent }\end{array}$ & {$[62]$} \\
\hline Tomato & Extraction with water and derivatize with the brominating reagent & {$[63,64]$} \\
\hline Green tea & Extraction with water and subjected to SPE. Derivatization with the brominating reagent & {$[65]$} \\
\hline $\begin{array}{l}\text { Commercial } \\
\text { frying oil }\end{array}$ & $\begin{array}{l}\text { Extraction with water and defatting with hexane, followed by being subjected to SPE. Derivatization with } \\
\text { xanthydrol solution and } 1 \mathrm{~mL} \text { of } \mathrm{HCl} \text { at } 40^{\circ} \mathrm{C} \text { in the dark, then slightly alkalinized with } \mathrm{KOH} \text { and followed by } \\
\text { saturated } \mathrm{NaCl} \text {. Then, AA derivative was extracted twice with EtAc. }\end{array}$ & {$[66]$} \\
\hline
\end{tabular}

TABLE 2: AA content in different food varieties.

\begin{tabular}{lcc}
\hline Food sample & AA level & Reference \\
\hline Potato crisps & $325 \mu \mathrm{g} / \mathrm{kg}$ & {$[67]$} \\
Breakfast cereals & $<62-803 \mu \mathrm{g} / \mathrm{kg}$ & {$[68]$} \\
Carbohydrate-rich food & $<20-2,528 \mu \mathrm{g} / \mathrm{kg}$ & {$[69]$} \\
Pizza, minced meat, and fried & $0-1,480 \mu \mathrm{g} / \mathrm{kg}$ & {$[70]$} \\
bacon & $11.4-36.2 \mu \mathrm{g} / \mathrm{L}$ & {$[71]$} \\
Espresso coffee & $102 \mu \mathrm{g} / \mathrm{kg}$ & {$[72]$} \\
Chocolate & $30-56 \mu \mathrm{g} / \mathrm{kg}$ & {$[65]$.} \\
Green tea & $2-516 \mu \mathrm{g} / \mathrm{kg}$ & {$[73]$} \\
Baby foods & $50 \mu \mathrm{g} / \mathrm{kg}-124$ & {$[73]$} \\
Tomato & $\mu \mathrm{g} / \mathrm{kg}$ & \\
\hline
\end{tabular}

results, exposure to a high dose of $25 \mathrm{mg} / \mathrm{kg}$ for 21 days caused a significant decrease in liver GSH level and total antioxidant in adult rats [89]. Furthermore, the accumulation of AA also resulted in increased serum level of liver enzymes, a decrease in superoxide dismutase and catalase activities, and increased total oxidants and malondialdehyde levels [8]. However, hepatotoxicity in humans is still very less.

\section{Mitigation Techniques of Acrylamide in Food}

Various AA mitigation techniques have been described in the literature, and a summary of those approaches is discussed in the following section. According to findings, this can be done by maintaining low AA formation throughout the heat processing and removal of already formed AA in finished products. Low AA formation could be expected through appropriate processing conditions, using agronomic and genetic approaches, pretreatments, and by adding specific additives, plant extracts, competitive inhibitors, and enzymes $[1,11,24,30,75,84]$.

5.1. Processing Conditions. In general, higher cooking temperatures, longer cooking times, relative humidity, and heat transfer medium are the processing factors that impact the AA formation in foods $[6,90]$. Several studies have discussed the impact of the time-temperature combination on AA formation. These researches illustrated those process parameters could be an effective way of AA minimization [91]. AA formation could be reduced by prolonged heating at low temperatures or by regulating the oven temperature as higher temperatures at the early stages followed by low temperatures at the final stage [92]. Prolonged heating at high temperatures 
generates low levels of AA due to degradation reactions $[91,92]$. Thermal processes involve low temperatures or water (as boiling or steam cooking) as the medium known to reduce the Maillard reactions and accordingly decrease AA formation [91]. Apart from that, water activity also influences the rate of AA formation. It has been demonstrated that no AA was observed when water is evaporated from the food completely [90]. In contrast, high AA formation was observed at a given temperature with low moisture in the food [91]. Furthermore, high relative humidity during baking was proved to be effective for the reduction of AA in bakery products. Low temperatures are suitable for foods that have high residual moisture. Moreover, AA formation in cereal products that have low moisture could be reduced by using deck ovens that transfer heat by conduction and radiation, then convection ovens, which are based on forced air circulation. Thus, the forced air circulation is accountable for quicker drying, and subsequently, the surface was increased, which enhances AA formation [92].

5.2. Agronomic and Genetic Approaches. Agronomic and genetic factors in raw materials could be altered to get lower reducing sugars and asparagine content. According to the literature, sulfur deficiency leads to the greatest asparagine accumulation in cereal grain, and in conditions of severe sulfur deprivation, asparagine can accumulate up to $50 \%$ of the total free amino acid [93]. Additionally, nitrogen fertilization resulted in a high level of free asparagine [94]. Moreover, sprouting is also affecting AA formation in cereal grain, as it leads to the degradation of starch and proteins, and the release of sugars and asparagine [95]. Sprouting of potato tubers can be prevented by storage at $4^{\circ} \mathrm{C}$, which results in cold sweetening in which starch is broken into reducing sugars. This can be overcome by storing at $12^{\circ} \mathrm{C}$ or spraying the harvest with chemical sprout suppressants [96]. Claus et al. [97] reported that bread prepared with sprouted grains had a $500 \%$ increment in AA compared to normal grains. Therefore, sprouted grains should not be used for bakery products [98, 99]. Furthermore, the maturity stage is also impacting the AA formation. Mature fruits comprise high reducing sugars than immature ones, which results in a higher AA formation [100].

Genetic modification is another way of minimizing AA in raw materials by the selection of cultivars and genetic factors such as raw materials with a low amount of asparagine and sugar levels. Asparaginase is the predominant enzyme involved in the hydrolysis of asparagine that results in forming of aspartate and ammonia [101]. Glutamine synthetase, asparagine synthetase, and asparaginase are the potential candidate genes that are involved in amino acid signaling either for manipulation by genetic modification or mutagenesis or for the development of genetic markers for breeding purposes [102].

5.3. Additives, Competitive Inhibitors, and Enzymes. Various types of additives, enzymes, competitive inhibitors, and plant extracts that have different inhibitory mechanisms can be used to mitigate AA formation $[1,103]$. Sulfites have been confirmed to be effective, based on the inhibition of the intermediate compounds in AA formation [104]. Proteins or amino acids (soy protein hydrolysates and sulfurcontaining amino acids) which competes with the precursors in food can be added to mitigate acrylamide formation; however, the mechanism depends on the nature of the amino acids [105]. The inhibitory effect of the sulfurcontaining amino acids is based on a Michael-type addition (nucleophilic addition) reaction between the SH group of the sulfur amino acids and AA [106]. Cysteine and glutathione were effectively proven results for the reduction of $\mathrm{AA}$ in olive ripe, potatoes, and grape juice respectively [107, 108].

Asparaginase is the key enzyme that hydrolyzes asparagine into aspartic acid and ammonia thus removing the precursor of AA from the cereals, potatoes, and bakery products while keeping the sensory characteristics of the final product. Asparaginase does not exist in humans but naturally does in some bacteria (E. coli, Erwinia), mold, plants, and some animals. At present microbial asparaginases, those from Aspergillus oryzae and Aspergillus niger are commercially available [101]. The activity of the enzyme depends on the concentration of the enzyme, $\mathrm{pH}$, incubation time, temperature, and product formulation. The action of asparaginase can be enhanced by combining it with another mitigation approach. Combine blanching with asparaginase immersion improves the AA reduction in potato chips [109].

Plant extracts consisting natural phenolics also show to have effective results for AA mitigation. Most of the plant extracts that include green tea, bamboo, mint, berry, grape extract, rosemary aqueous extract, oregano, and pomegranate flower have reported a significant decrease of AA [5, $110,111]$. Their inhibitory action mainly depends on phenolic compounds such as flavonoids, phenolic acids, and tannins [112], and their antioxidant power, carbonyl trapping activity, amino acid precipitation effect, and other supposed mechanisms of actions [113]. According to the literature, sometimes, antioxidants can either promote or reduce AA formation, irrespective of antioxidant power [5]. For example, naringenin, with weak antioxidant activity, can strongly block AA formation but curcumin as a potent antioxidant facilitates AA production $[5,114]$. Moreover, sulfurous compounds like garlic and nitrogenous compound, piperine, weakly reduce AA in foods [115].

Organic acids such as citric, tartaric, acetic, and lactic acid were shown to have effective results in the mitigation of AA in gingerbread, biscuits, and potatoes by lowering the $\mathrm{pH}$ that creates unfavorable conditions [104]. Since acids lead to alterations of the organoleptic qualities and have synergistic effects, the added amount is limited. Several studies have indicated that B vitamins such as nicotinic acid (B3), pyridoxamine (B6), pyridoxine (B6), and biotin (B7) have shown some effective reduction of AA. Vitamin B3 was effective for fried potato strips; however, vitamin B7 and thiamine (B1) were not efficient in the reduction of AA in a mixture of potato flour and semolina $[114,115]$. Recent studies found that hydrocolloids such as alginic acid and pectin decrease the amount of AA in fried potato strips [116]. In contrast, hydrocolloids such as carob gum, carrageenan, hydroxypropyl di starch phosphate, and xanthan gum increase the quantity of AA [117]. The inhibition mechanism is based on the 
molecular movements to make interactions between hydrocolloids and the precursors of AA [118].

5.4. Blanching. The blanching of potatoes before frying has been found very effective in minimizing AA [104]. Blanching helps to remove sugars from potatoes, thus reducing the number of AA precursors. Mestdagh et al. [119] reported that hightemperature short-time blanching proved to be more effective than blanching at low temperatures for a long time.

5.5. Fermentation. Fermentation with yeast has been reported to the consumption of the asparagine precursor content in bread [120]. Wang et al. [121] reported that about $40-60 \%$ asparagine can be reduced by yeast fermentation whereas the contents of reducing sugars are increased. Nevertheless, sourdough fermentation negatively affects the reduction of asparagine by yeast and leads to an increase in the AA [121]. Lactic acid fermentation in potatoes increases asparagine contents and reduces the contents of reducing sugars, which, accordingly, result in decreasing AA contents [122].

5.6. Encapsulation. Encapsulation is a new approach for AA mitigation, based on the controlled release of reactants during the processing time. The encapsulation of sodium chloride is an effective strategy to control the formation of some precursors of the Maillard browning [123]. Commonly, monovalent and divalent cations minimize the AA formation by sugar decomposition. Consequently, those cations alter the reaction pathway that leads to the formation of HMF or furan formation. Sodium ions determine the formation of fructofuranosyl cation which is one of the key precursors of HMF [124]. This strategy has been broadly illustrated in partially dehydrated cherry, tomato and grapefruits, cookies, and other bakery products [123-125]. Iron and ascorbic acids also can be used for encapsulation purposes [126]. AA formation is influenced by metal ions, through promoting oxidation reaction in the Maillard browning that leads to the formation of dicarbonyl compounds [127]. Nevertheless, in some cases, metal ions can suppress the Maillard reaction or can be effectively used to catalyze the precipitation and the successive removal of the brown materials, which leads to AA formation [126]. Ascorbic acid is more sensitive to oxidation and is implied in the formation of furan [127]. Encapsulation of these compounds in thermally processed food is thus interesting to preserve them from thermal degradation. The addition of flaxseed oil nanocapsules in bread protects them from oxidation which leads to an increase in the nutritional value of bread and less AA and HMF without affecting the sensory properties [128].

Postprocess approaches are now being used to eliminate produced AA during food processing, but it needs technological advancement to continue with high cost. Several studies (i) remove AA under stimulated gastrointestinal conditions using a dynamic system [129] and (ii) apply a hydration step followed by a vacuum drying for finished food with less moisture [19]. Most of the mitigation strategies directly affect the organoleptic properties; thus, a combination of two or more approaches may lead to improved mitigation efficiency and sensorial problems in food commodities.

\section{Conclusion and Future Prospective}

Acrylamide is a heat-induced toxic substance that was discovered in food commodities in 2002; factors that affect its formation, formation mechanisms, AA detection techniques, health impacts, and mitigation strategies were broadly discussed in this paper. For mitigation purposes, process parameters, novel, integrated processing techniques, use of additives, and different pre- and postprocessing treatments have been reported in several studies. Nevertheless, the same approach is not applicable in all food categories; it depends on food compositions and different product technologies. Also, there is no fully accepted extraction method of AA from foodstuffs. Further, more studies will have to be conducted to investigate the extraction methods of different kinds of foods on AA.

The Food and Agriculture Organization (FAO) and WHO have found a global network to permit all interested parties to communicate information with regard to ongoing studies on acrylamide in food. According to the European Food Safety Agency, areas of tumors, dose-response, and mode of action for each of the tumors, identified in animal test species, species sensitivity, physiologically based pharmacokinetic (PBPK) modeling, epidemiological studies on additional populations or specific groups of the population, and additional cancer sites to draw firm conclusions on the cancer risk associated to acrylamide exposure should be investigated. Due to the very limited data on dietary exposure, actual acrylamide exposures should be validated by the Food Frequency Questionnaires (FFQ) coupled with biomarkers.

HMF is also a heat-induced toxic intermediate that participates in the formation of AA in the food matrix. Investigation of the extent of HMF and related carcinogenicity in animals, epidemiological data associated with dietary exposure to HMF, and increased cancer risk mitigation approaches to reduce HMF content in foods should be further studied.

Moreover, community awareness about the dangers of acrylamide along with possible ways to reduce its formation needs to be increased. Furthermore, government agencies and the industry about the dangers and possible ways of reducing this food contaminant must be provided. Most of the mitigation strategies were investigated to reduce acrylamide under the research level. Thus, implementing suitable mitigation strategies at the industrial scale and applying good practices for household cooking or changing food behaviors and consumption patterns are most important to eliminate the adverse consequence of acrylamide.

\section{Data Availability}

The numerical data used to support the findings of this study are available from the corresponding author upon request.

\section{Conflicts of Interest}

The authors declare that the research was conducted in the absence of any financial or commercial relationships that 
could be created as potential conflicts of interest regarding the publication of this paper.

\section{Authors' Contributions}

Dilini N. Perera is responsible for conceptualization, methodology, investigation, formal analysis, data curation, writing-original draft, and writing-review and editing. Geeth G. Hewavitharana is responsible for conceptualization, methodology, investigation, formal analysis, data curation, writing-original draft, and writing-review and editing. S.B. Navaratne is responsible for conceptualization, writingreview and editing, resources, and supervision.

\section{References}

[1] M. Friedman, "Acrylamide: inhibition of formation in processed food and mitigation of toxicity in cells, animals, and humans," Food \& Function, vol. 6, no. 6, pp. 1752-1772, 2015.

[2] V. Gökmen and T. K. Palazoğlu, "Acrylamide formation in foods during thermal processing with a focus on frying," Food and Bioprocess Technology, vol. 1, no. 1, pp. 35-42, 2008.

[3] D. Pacetti, E. Gil, N. G. Frega et al., "Acrylamide levels in selected Colombian foods," Food Additives \& Contaminants: Part B, vol. 8, no. 2, pp. 99-105, 2015.

[4] D. R. Lineback, J. R. Coughlin, and R. H. Stadler, "Acrylamide in foods: a review of the science and future considerations," Annual Review of Food Science and Technology, vol. 3, no. 1, pp. 15-35, 2012.

[5] C. Jin, X. Wu, and Y. Zhang, "Relationship between antioxidants and acrylamide formation: a review," Food Research International, vol. 51, no. 2, pp. 611-620, 2013.

[6] J. Keramat, A. LeBail, C. Prost, and M. Jafari, "Acrylamide in baking products: a review article," Food and Bioprocess Technology, vol. 4, no. 4, pp. 530-543, 2011.

[7] M. Mencin, H. Abramovič, R. Vidrih, and M. Schreiner, "Acrylamide levels in food products on the Slovenian market," Food Control, vol. 114, article 107267, 2020.

[8] T. Krishnakumar and R. Visvanathan, "Acrylamide in food products: a review," Journal of Food Processing \& Technology, vol. 5, no. 7, p. 1, 2014.

[9] A. P. Arisseto and E. Vicente, "Estimate of acrylamide intake from coffee and health risk assessment," in Coffee in Health and Disease Prevention, pp. 575-584, Academic Press, London, 2015.

[10] D. P. Balagiannis, D. S. Mottram, J. Higley, G. Smith, B. L. Wedzicha, and J. K. Parker, "Kinetic modelling of acrylamide formation during the finish-frying of french fries with variable maltose content," Food Chemistry, vol. 284, pp. 236244, 2019.

[11] C. P. Passos, S. S. Ferreira, A. Serôdio et al., "Pectic polysaccharides as an acrylamide mitigation strategy - competition between reducing sugars and sugar acids," Food Hydrocolloids, vol. 81, pp. 113-119, 2018.

[12] D. Laroque, C. Inisan, C. Berger, É. Vouland, L. Dufossé, and F. Guérard, "Kinetic study on the Maillard reaction. Consideration of sugar reactivity," Food Chemistry, vol. 111, no. 4, pp. 1032-1042, 2008.

[13] L. Lamberts, I. Rombouts, and J. A. Delcour, "Study of nonenzymic browning in $\alpha$-amino acid and $\gamma$ aminobutyric acid/- sugar model systems," Food Chemistry, vol. 111, no. 3, pp. 738-744, 2008.

[14] X. M. Chen and D. D. Kitts, "Identification and quantification of $\alpha$-dicarbonyl compounds produced in different sugaramino acid Maillard reaction model systems," Food Research International, vol. 44, no. 9, article 27752782, pp. 2775-2782, 2011.

[15] N. Muttucumaru, A. J. Keys, M. A. Parry, S. J. Powers, and N. G. Halford, "Photosynthetic assimilation of $14 \mathrm{C}$ into amino acids in potato (Solanum tuberosum) and asparagine in the tubers," Planta, vol. 239, no. 1, pp. 161-170, 2014.

[16] P. R. Shewry, F. J. Zhao, G. B. Gowa et al., "Sulphur nutrition differentially affects the distribution of asparagine in wheat grain," Journal of Cereal Science, vol. 50, no. 3, pp. 407-409, 2009.

[17] T. Kocadağlı, N. Göncüoğlu, A. Hamzalığlu, and V. Gökmen, "In depth study of acrylamide formation in coffee during roasting: role of sucrose decomposition and lipid oxidation," Food \& Function, vol. 3, no. 9, pp. 970-975, 2012.

[18] K. De Vleeschouwer, I. Van der Plancken, A. Van Loey, and M. E. Hendrickx, "Kinetics of acrylamide formation/elimination reactions as affected by water activity," Biotechnology Progress, vol. 23, no. 3, pp. 722-728, 2007.

[19] M. Anese, M. Suman, and M. C. Nicoli, "Acrylamide removal from heated foods," Food Chemistrty, vol. 119, no. 2, pp. 791794, 2010.

[20] S. Stojanovska and J. Tomovska, "Factors influence to formation of acrylamide in food," Journal of Hygienic Engineering and Design, vol. 13, pp. 10-15, 2015.

[21] M. G. Corradini and M. Peleg, "Linear and non-linear kinetics in the synthesis and degradation of acrylamide in foods and model systems," Critical Reviews in Food Science and Nutrition, vol. 46, no. 6, pp. 489-517, 2007.

[22] S. Damodaran and K. L. Parkin, Fennema's food chemistry, CRC press, 2017.

[23] B. Matthäus, N. U. Haase, and K. Vosmann, "Factors affecting the concentration of acrylamide during deepfat frying of potatoes," European Journal of Lipid Science and Technology, vol. 106, no. 11, pp. 793-801, 2004.

[24] A. A. Maan, M. A. Anjum, M. K. I. Khan et al., "Acrylamide formation and different mitigation strategies during food processing-a review," Food Reviews International, vol. 37, pp. 1-18, 2020.

[25] Y. Zhang, J. Jiao, Y. Ren, X. Wu, and Y. Zhang, "Determination of acrylamide in infant cereal-based foods by isotope dilution liquid chromatography coupled with electrospray ionization tandem mass spectrometry," Analytica Chimica Acta, vol. 551, no. 1-2, pp. 150-158, 2005.

[26] J. Keramat, A. LeBail, C. Prost, and N. Soltanizadeh, "Acrylamide in foods: chemistry and analysis. A review," Food and Bioprocess Technology, vol. 4, no. 3, pp. 340-363, 2011.

[27] S. Eriksson, Acrylamide in Food Products: Identification, Formation and Analytical Methodology, Doctoral dissertation, Institutionen för miljökemi, 2005.

[28] D. V. Zyzak, R. A. Sanders, M. Stojanovic et al., "Acrylamide formation mechanism in heated foods," Journal of Agricultural and Food Chemistry, vol. 51, no. 16, pp. 4782-4787, 2003.

[29] M. Granvogl and P. Schieberle, "Thermally generated 3aminopropionamide as a transient intermediate in the 
formation of acrylamide," Journal of Agricultural and Food Chemistry, vol. 54, no. 16, pp. 5933-5938, 2006.

[30] Y. Xu, B. Cui, R. Ran et al., "Risk assessment, formation, and mitigation of dietary acrylamide: current status and future prospects," Food and Chemical Toxicology, vol. 69, pp. 1-12, 2014.

[31] G. P. Rizzi, “The Strecker degradation of amino acids: newer avenues for flavor formation," Food Reviews International, vol. 24, no. 4, pp. 416-435, 2008.

[32] D. S. Mottram, B. L. Wedzicha, and A. T. Dodson, "Acrylamide is formed in the Maillard reaction," Nature, vol. 419, no. 6906, pp. 448-449, 2002.

[33] A. B. Das and P. P. Srivastav, "Acrylamide in snack foods," Toxicology Mechanisms and Methods, vol. 22, no. 3, pp. 163-169, 2011.

[34] H. R. Katragadda, A. Fullana, S. Sidhu, and Á. A. CarbonellBarrachina, "Emissions of volatile aldehydes from heated cooking oils," Food Chemistry, vol. 120, no. 1, pp. 59-65, 2010.

[35] G. Daniali, S. Jinap, P. Hajeb, M. Sanny, and C. P. Tan, "Acrylamide formation in vegetable oils and animal fats during heat treatment," Food Chemistry, vol. 212, pp. 244-249, 2016.

[36] A. A. Elbashir, M. M. A. Omar, W. A. W. Ibrahim, O. J. Schmitz, and H. Y. Aboul-Enein, "Acrylamide analysis in food by liquid chromatographic and gas chromatographic methods," Critical Reviews in Analytical Chemistry, vol. 44, no. 2, pp. 107-141, 2014.

[37] T. Wenzl, L. Karasek, J. Rosen et al., "Collaborative trial validation study of two methods, one based on high performance liquid chromatography-tandem mass spectrometry and on gas chromatography-mass spectrometry for the determination of acrylamide in bakery and potato products," Journal of Chromatography A, vol. 1132, no. 1-2, pp. 211-218, 2006.

[38] Y. Zhu, G. Li, Y. Duan, S. Chen, C. Zhang, and Y. Li, “Application of the standard addition method for the determination of acrylamide in heat-processed starchy foods by gas chromatography with electron capture detector," Food Chemistry, vol. 109, no. 4, pp. 899-908, 2008.

[39] T. Wenzl, M. B. De La Calle, and E. Anklam, "Analytical methods for the determination of acrylamide in food products: a review," Food Additives and Contaminants, vol. 20, no. 10, pp. 885-902, 2003.

[40] N. J. Nielsen, K. Granby, R. V. Hedegaard, and L. H. Skibsted, "A liquid chromatography - tandem mass spectrometry method for simultaneous analysis of acrylamide and the precursors, asparagine and reducing sugars in bread," Analytica Chimica Acta, vol. 557, no. 1-2, pp. 211-220, 2006.

[41] L. Castle and S. Eriksson, "Analytical methods used to measure acrylamide concentrations in foods," Journal of AOAC International, vol. 88, no. 1, pp. 274-284, 2005.

[42] T. Delatour, A. Périsset, T. Goldmann, S. Riediker, and R. H. Stadler, "Improved sample preparation to determine acrylamide in difficult matrixes such as chocolate powder, cocoa, and coffee by liquid chromatography tandem mass spectroscopy," Journal of Agricultural and Food Chemistry, vol. 52, no. 15 , pp. 4625-4631, 2004.

[43] V. Gökmen, F. J. Morales, B. Ataç, A. Serpen, and G. ArribasLorenzo, "Multiple-stage extraction strategy for the determination of acrylamide in foods," Journal of Food Composition and Analysis, vol. 22, no. 2, pp. 142-147, 2009.
[44] S. Cavalli, R. Maurer, and F. Hofler, "Fast determination of acrylamide in food samples using accelerated solvent extraction $\left(\mathrm{ASE}^{\circledR}\right)$ followed by ion chromatography with UV or MS detection," LC GC North America, vol. 21, Supplement_2, pp. 35-36, 2003.

[45] H. Z. Şenyuva and V. Gökmen, "Interference-free determination of acrylamide in potato and cereal-based foods by a laboratory validated liquid chromatography-mass spectrometry method," Food Chemistry, vol. 97, no. 3, pp. 539-545, 2006

[46] M. M. A. Omar, W. A. Wan Ibrahim, and A. A. Elbashir, "Sol-gel hybrid methyltrimethoxysilane-tetraethoxysilane as a new dispersive solid-phase extraction material for acrylamide determination in food with direct gas chromatographymass spectrometry analysis," Food Chemistry, vol. 158, pp. 302-309, 2014.

[47] M. Arabi, M. Ghaedi, and A. Ostovan, "Development of dummy molecularly imprinted based on functionalized silica nanoparticles for determination of acrylamide in processed food by matrix solid phase dispersion," Food Chemistry, vol. 210, pp. 78-84, 2016.

[48] M. Surma, A. Sadowska-Rociek, E. Cieślik, and K. SznajderKatarzyńska, "Optimization of QuEChERS sample preparation method for acrylamide level determination in coffee and coffee substitutes," Microchemical Journal, vol. 131, pp. 98-102, 2017.

[49] E. Pourmand, E. Ghaemi, and N. Alizadeh, "Determination of acrylamide in potato-based foods using headspace solidphase microextraction based on nanostructured polypyrrole fiber coupled with ion mobility spectrometry: a heat treatment study," Analytical Methods, vol. 9, no. 35, pp. 51275134, 2017.

[50] F. Xu, L. Zou, Y. Liu, Z. Zhang, and C. N. Ong, "Enhancement of the capabilities of liquid chromatography-mass spectrometry with derivatization: general principles and applications," Mass Spectrometry Reviews, vol. 30, no. 6, pp. 1143-1172, 2011.

[51] K. Mastovska and S. J. Lehotay, "Rapid sample preparation method for LC- MS/MS or GC- MS analysis of acrylamide in various food matrices," Journal of Agricultural and Food Chemistry, vol. 54, no. 19, pp. 7001-7008, 2006.

[52] Y. Zhang, G. Zhang, and Y. Zhang, "Occurrence and analytical methods of acrylamide in heat-treated foods: review and recent developments," Journal of Chromatography A, vol. 1075, no. 1-2, pp. 1-21, 2005.

[53] V. Gökmen and H. Z. Şenyuva, "A generic method for the determination of acrylamide in thermally processed foods," Journal of Chromatography A, vol. 1120, no. 1-2, pp. 194198, 2006.

[54] A. F. Lagalante and M. A. Felter, "Silylation of acrylamide for analysis by solid-phase microextraction/gas chromatography/ion-trap mass spectrometry," Journal of Agricultural and Food Chemistry, vol. 52, no. 12, pp. 3744-3748, 2004.

[55] H. Ono, Y. Chuda, M. Ohnishi-Kameyama et al., "Analysis of acrylamide by LC-MS/MS and GC-MS in processed Japanese foods," Food Additives \& Contaminants, vol. 20, no. 3, pp. 215-220, 2003.

[56] L. Molina-Garcia, C. S. P. Santos, A. Melo, J. O. Fernandes, S. C. Cunha, and S. Casal, "Acrylamide in chips and French fries: a novel and simple method using xanthydrol for its GC-MS determination," Food Analytical Methods, vol. 8, no. 6, pp. 1436-1445, 2015. 
[57] C. G Hamlet, S. M Jayaratne, and P. A Sadd, "Rapid, sensitive and selective analysis of acrylamide in cereal products using bromination and GC/MS/MS," Czech Journal of Food Sciences, vol. 22, no. SI - Chem. Reactions in Foods V, pp. S290-S293, 2004.

[58] E. Norouzi, M. Kamankesh, A. Mohammadi, and A. Attaran, "Acrylamide in bread samples: determining using ultrasonicassisted extraction and microextraction method followed by gas chromatography-mass spectrometry," Journal of Cereal Science, vol. 79, pp. 1-5, 2018.

[59] A. Nematollahi, M. Kamankesh, H. Hosseini, J. Ghasemi, F. Hosseini-Esfahani, and A. Mohammadi, "Investigation and determination of acrylamide in the main group of cereal products using advanced microextraction method coupled with gas chromatography-mass spectrometry," Journal of Cereal Science, vol. 87, pp. 157-164, 2019.

[60] A. Pittet, A. Périsset, and J. M. Oberson, “Trace level determination of acrylamide in cereal-based foods by gas chromatography-mass spectrometry," Journal of Chromatography $A$, vol. 1035, no. 1, pp. 123-130, 2004.

[61] F. Esposito, E. Fasano, A. De Vivo, S. Velotto, F. Sarghini, and T. Cirillo, "Processing effects on acrylamide content in roasted coffee production," Food Chemistry, vol. 319, article 126550, 2020.

[62] M. F. Cengiz and C. P. Boyacı Gündüz, "An eco-friendly, quick and cost-effective method for the quantification of acrylamide in cereal-based baby foods," Journal of the Science of Food and Agriculture, vol. 94, no. 12, pp. 25342540, 2014.

[63] L. Castle, M. J. Campos, and J. Gilbert, "Determination of acrylamide monomer in hydroponically grown tomato fruits by capillary gas chromatography_mass spectrometry," Journal of the Science of Food and Agriculture, vol. 54, no. 4, pp. 549-555, 1991.

[64] A. Becalski, B. P. Y. Lau, D. Lewis, S. W. Seaman, and W. F. Sun, "Determination of acrylamide in various food matrices," in Chemistry and safety of acrylamide in food, pp. 271-284, Springer, Boston, MA, 2005.

[65] Y. Mizukami, K. Kohata, Y. Yamaguchi et al., "Analysis of acrylamide in green tea by gas chromatography- mass spectrometry," Journal of Agricultural and food Chemistry, vol. 54, no. 19, pp. 7370-7377, 2006.

[66] N. Totani, M. Yawata, M. Takada, and M. Moriya, "Acrylamide content of commercial frying oil," Journal of Oleo Science, vol. 56, no. 2, pp. 103-106, 2007.

[67] E. Bermudo, O. Núñez, L. Puignou, and M. T. Galceran, "Analysis of acrylamide in food products by in-line preconcentration capillary zone electrophoresis," Journal of Chromatography A, vol. 1129, no. 1, pp. 129-134, 2006.

[68] E. Bermudo, E. Moyano, L. Puignou, and M. T. Galceran, "Liquid chromatography coupled to tandem mass spectrometry for the analysis of acrylamide in typical Spanish products," Talanta, vol. 76, no. 2, pp. 389-394, 2008.

[69] A. P. Arisseto, M. C. Toledo, Y. Govaert et al., "Determination of acrylamide levels in selected foods in Brazil," Food Additives and Contaminants, vol. 24, no. 3, pp. 236-241, 2007.

[70] S. Eerola, K. Hollebekkers, A. Hallikainen, and K. Peltonen, "Acrylamide levels in Finnish foodstuffs analysed with liquid chromatography tandem mass spectrometry," Molecular Nutrition \& Food Research, vol. 51, no. 2, pp. 239-247, 2007.
[71] C. Soares, S. Cunha, and J. Fernandes, "Determination of acrylamide in coffee and coffee products by GC-MS using an improved SPE clean-up," Food Additives and Contaminants, vol. 23, no. 12, pp. 1276-1282, 2006.

[72] O. Pardo, V. Yusà, C. Coscollà, N. León, and A. Pastor, "Determination of acrylamide in coffee and chocolate by pressurised fluid extraction and liquid chromatography-tandem mass spectrometry," Food Additives and Contaminants, vol. 24, no. 7, pp. 663-672, 2007.

[73] F. Tateo, M. Bononi, and G. Andreoli, "Acrylamide levels in cooked rice, tomato sauces and some fast food on the Italian market," Journal of Food Composition and Analysis, vol. 20, no. 3-4, pp. 232-235, 2007.

[74] E. Capuano and V. Fogliano, "Acrylamide and 5hydroxymethylfurfural (HMF): A review on metabolism, toxicity, occurrence in food and mitigation strategies," LWTFood Science and Technology, vol. 44, no. 4, pp. 793-810, 2011.

[75] Q. Wei, J. Li, X. Li, L. Zhang, and F. Shi, "Reproductive toxicity in acrylamide-treated female mice," Reproductive Toxicology, vol. 46, pp. 121-128, 2014.

[76] International Agency for Research on Cancer, IARC, Monographs on the evaluation of carcinogenic risks to humans: some industrial chemicals, vol. 60, Acrylamide. International Agency for Research on Cancer-IARC, 1994.

[77] L. Busk, "Acrylamide - A case study on risk analysis," Food Control, vol. 21, no. 12, pp. 1677-1682, 2010.

[78] P. Erkekoglu and T. Baydar, "Acrylamide neurotoxicity," Nutritional Neuroscience, vol. 17, no. 2, pp. 49-57, 2013.

[79] M. Pennisi, G. Malaguarnera, V. Puglisi, L. Vinciguerra, M. Vacante, and M. Malaguarnera, "Neurotoxicity of acrylamide in exposed workers," International Journal of Environmental Research and Public Health, vol. 10, no. 9, pp. 38433854, 2013.

[80] G. Arribas-Lorenzo and F. J. Morales, "Recent insights in acrylamide as carcinogen in foodstuffs," in Advances in Molecular Toxicology Volume 6, pp. 163-193, Elsevier, 2012.

[81] N. Rajeh, H. Ali, and S. ElAssouli, "Protective effect of 5aminosalicylic acid on acrylamide toxicity in the testis and blood leukocytes of the rat," Kuwait Medical Journal, vol. 46, no. 1, pp. 32-43, 2014.

[82] L. Ao and J. Cao, "Genotoxicity of acrylamide and glycidamide: a review of the studies by HPRT gene and TK gene mutation assays," Genes and Environment, vol. 34, no. 1, pp. 1-8, 2012.

[83] L. Rifai and F. A. Saleh, "A review on acrylamide in food: occurrence, toxicity, and mitigation strategies," International Journal of Toxicology, vol. 39, no. 2, pp. 93-102, 2020.

[84] J. G. Hogervorst, B. J. Baars, L. J. Schouten, E. J. Konings, R. A. Goldbohm, and P. A. van den Brandt, "The carcinogenicity of dietary acrylamide intake: a comparative discussion of epidemiological and experimental animal research," Critical Reviews in Toxicology, vol. 40, no. 6, pp. 485-512, 2010.

[85] R. R. Maronpot, R. J. M. M. Thoolen, and B. Hansen, "Twoyear carcinogenicity study of acrylamide in Wistar Han rats with in utero exposure," Experimental and Toxicologic Pathology, vol. 67, no. 2, pp. 189-195, 2015.

[86] M. Friedman, "Chemistry, biochemistry, and safety of acrylamide. A review," Journal of Agricultural and Food Chemistry, vol. 51, no. 16, pp. 4504-4526, 2003. 
[87] A. Shipp, G. Lawrence, R. Gentry et al., "Acrylamide: review of toxicity data and dose-response analyses for cancer and noncancer effects," Critical Reviews in Toxicology, vol. 36, no. 6-7, pp. 481-608, 2008.

[88] D. R. Lineback and J. M. Jones, "Acrylamide in foods," Nutrition Today, vol. 46, no. 5, pp. 216-223, 2011.

[89] A. A. Allam, A. W. El-Ghareeb, M. Abdul-Hamid, A. El Bakery, M. Gad, and M. Sabri, "Effect of prenatal and perinatal acrylamide on the biochemical and morphological changes in liver of developing albino rat," Archives of Toxicology, vol. 84, no. 2, pp. 129-141, 2010.

[90] P. Rydberg, S. Eriksson, E. Tareke, P. Karlsson, L. Ehrenberg, and M. Törnqvist, "Factors that influence the acrylamide content of heated foods," in Chemistry and safety of acrylamide in food, pp. 317-328, Springer, Boston, MA, 2005.

[91] L. Ahrné, C. G. Andersson, P. Floberg, J. Rosén, and H. Lingnert, "Effect of crust temperature and water content on acrylamide formation during baking of white bread: Steam and falling temperature baking," LWT-Food science and Technology, vol. 40, no. 10, pp. 1708-1715, 2007.

[92] F. Robert, G. Vuataz, P. Pollien et al., “Acrylamide formation from asparagine under low moisture Maillard reaction conditions. 2. Crystalline vs amorphous model systems," Journal of Agricultural and Food Chemistry, vol. 53, no. 11, pp. 46284632, 2005.

[93] V. Gökmen, T. K. Palazoğlu, and H. Z. Şenyuva, "Relation between the acrylamide formation and time-temperature history of surface and core regions of French fries," Journal of Food Engineering, vol. 77, no. 4, pp. 972-976, 2006.

[94] M. Anese, M. Suman, and M. C. Nicoli, "Technological strategies to reduce acrylamide levels in heated foods," Food Engineering Reviews, vol. 1, no. 2, pp. 169-179, 2009.

[95] N. G. Halford, N. Muttucumaru, T. Y. Curtis, and M. A. Parry, "Genetic and agronomic approaches to decreasing acrylamide precursors in crop plants," Food Additives and Contaminants, vol. 24, no. 1, pp. 26-36, 2007.

[96] P. Martinek, K. Klem, M. Vanova et al., "Effects of nitrogen nutrition, fungicide treatment and wheat genotype on free asparagine and reducing sugars content as precursors of acrylamide formation in bread," Plant, Soil and Environment, vol. 55, no. 5, pp. 187-195, 2009.

[97] A. Claus, R. Carle, and A. Schieber, "Acrylamide in cereal products: a review," Journal of Cereal Science, vol. 47, no. 2, pp. 118-133, 2008.

[98] P. B. Bhaskar, L. Wu, J. S. Busse et al., "Suppression of the vacuolar invertase gene prevents cold-induced sweetening in potato," Plant Physiology, vol. 154, no. 2, pp. 939-948, 2010.

[99] A. Claus, P. Schreiter, A. Weber et al., "Influence of agronomic factors and extraction rate on the acrylamide contents in yeast-leavened breads," Journal of agricultural and food chemistry, vol. 54, no. 23, pp. 8968-8976, 2006.

[100] G. Daniali, S. Jinap, N. L. Hanifah, and P. Hajeb, “The effect of maturity stages of banana on the formation of acrylamide in banana fritters," Food Control, vol. 32, no. 2, pp. 386-391, 2013.

[101] F. Pedreschi, S. Mariotti, K. Granby, and J. Risum, “Acrylamide reduction in potato chips by using commercial asparaginase in combination with conventional blanching," $L W T$ Food Science and Technology, vol. 44, no. 6, pp. 1473-1476, 2011.
[102] S. Raffan and N. G. Halford, "Acrylamide in food: progress in and prospects for genetic and agronomic solutions," Annals of Applied Biology, vol. 175, no. 3, pp. 259-281, 2019.

[103] C. Rannou, D. Laroque, E. Renault, C. Prost, and T. Sérot, "Mitigation strategies of acrylamide, furans, heterocyclic amines and browning during the Maillard reaction in foods," Food Research International, vol. 90, pp. 154-176, 2016.

[104] J. L. A. Dagostin, "Blanching as an acrylamide mitigation technique," in New Perspectives on Food Blanching, pp. 95122, Springer, Cham, 2017.

[105] G. Baskar and R. Aiswarya, "Overview on mitigation of acrylamide in starchy fried and baked foods," Journal of the Science of Food and Agriculture, vol. 98, no. 12, pp. 4385-4394, 2018.

[106] D. A. Augustine and G. A. Bent, "Reducing acrylamide exposure: a review of the application of sulfur-containing compounds-a Caribbean outlook," European Journal of Nutrition \& Food Safety, vol. 9, pp. 192-209, 2019.

[107] F. J. Casado, A. H. Sánchez, and A. Montaño, "Reduction of acrylamide content of ripe olives by selected additives," Food Chemistry, vol. 119, no. 1, pp. 161-166, 2010.

[108] F. J. Hidalgo, R. M. Delgado, and R. Zamora, "Positive interaction between amino and sulfhydryl groups for acrylamide removal," Food Research International, vol. 44, no. 4, pp. 1083-1087, 2011.

[109] P. R. Krishnapura, P. D. Belur, and S. Subramanya, "A critical review on properties and applications of microbial l-asparaginases," Critical Reviews in Microbiology, vol. 42, no. 5, pp. 720-737, 2016.

[110] Y. Liu, P. Wang, F. Chen et al., "Role of plant polyphenols in acrylamide formation and elimination," Food Chemistry, vol. 186, pp. 46-53, 2015.

[111] J. Bassama, P. Brat, P. Bohuon, R. Boulanger, and Z. Günata, "Study of acrylamide mitigation in model system: effect of pure phenolic compounds," Food Chemistry, vol. 123, no. 2, pp. 558-562, 2010.

[112] N. Kahkeshani, S. Saeidnia, and M. Abdollahi, "Role of antioxidants and phytochemicals on acrylamide mitigation from food and reducing its toxicity," Journal of Food Science and Technology, vol. 52, no. 6, pp. 3169-3186, 2015.

[113] A. Yashin, Y. Yashin, X. Xia, and B. Nemzer, “Antioxidant activity of spices and their impact on human health: a review," Antioxidants, vol. 6, no. 3, p. 70, 2017.

[114] X. Zeng, K. W. Cheng, Y. Jiang et al., "Inhibition of acrylamide formation by vitamins in model reactions and fried potato strips," Food Chemistry, vol. 116, no. 1, pp. 34-39, 2009.

[115] D. Wong, K. W. Cheng, and M. Wang, "Inhibition of heterocyclic amine formation by water-soluble vitamins in Maillard reaction model systems and beef patties," Food Chemistry, vol. 133, no. 3, pp. 760-766, 2012.

[116] A. al-Asmar, D. Naviglio, C. V. L. Giosafatto, and L. Mariniello, "Hydrocolloid-based coatings are effective at reducing acrylamide and oil content of French fries," Coatings, vol. 8, no. 4, p. 147, 2018.

[117] X. Zeng, K. W. Cheng, Y. Du et al., "Activities of hydrocolloids as inhibitors of acrylamide formation in model systems and fried potato strips," Food Chemistry, vol. 121, no. 2, pp. 424-428, 2010.

[118] R. M. Mousa, "Simultaneous mitigation of 4 (5)methylimidazole, acrylamide, and 5 hydroxymethylfurfural in ammonia 
biscuits by supplementing with food hydrocolloids," Food Science \& Nutrition, vol. 7, no. 12, pp. 3912-3921, 2019.

[119] F. Mestdagh, T. De Wilde, S. Fraselle et al., "Optimization of the blanching process to reduce acrylamide in fried potatoes," LWT-Food Science and Technology, vol. 41, no. 9, pp. 16481654, 2008.

[120] S. Wang, J. Yu, Q. Xin, S. Wang, and L. Copeland, "Effects of starch damage and yeast fermentation on acrylamide formation in bread," Food Control, vol. 73, pp. 230-236, 2017.

[121] T. Katsaiti and K. Granby, "Mitigation of the processing contaminant acrylamide in bread by reducing asparagine in the bread dough," Food Additives \& Contaminants: Part A, vol. 33, no. 9, pp. 1402-1410, 2016.

[122] H. Blom, P. Baardseth, T. W. Sundt, and E. Slinde, "Lactic acid fermentation reduces acrylamide formed during production of fried potato products," Aspects of Applied Biology, vol. 97, pp. 65-71, 2009.

[123] A. Fiore, A. D. Troise, B. Ataç Mogol et al., "Controlling the Maillard reaction by reactant encapsulation: sodium chloride in cookies," Journal of Agricultural and Food Chemistry, vol. 60, no. 43, pp. 10808-10814, 2012.

[124] A. D. Troise and V. Fogliano, "Reactants encapsulation and Maillard reaction," Trends in Food Science \& Technology, vol. 33, no. 1, pp. 63-74, 2013.

[125] K. S. Özdemir and V. Gökmen, "Effect of microencapsulation on the reactivity of ascorbic acid, sodium chloride and vanillin during heating," Journal of Food Engineering, vol. 167, pp. 204-209, 2015.

[126] D. T. Ramonaitytè, M. Keršienè, A. Adams, K. A. Tehrani, and N. De Kimpe, "The interaction of metal ions with Maillard reaction products in a lactose- glycine model system," Food Research International, vol. 42, no. 3, pp. 331-336, 2009.

[127] F. Zaera, "Nanostructured materials for applications in heterogeneous catalysis," Chemical Society Reviews, vol. 42, no. 7, pp. 2746-2762, 2013.

[128] V. Gökmen, B. A. Mogol, R. B. Lumaga, V. Fogliano, Z. Kaplun, and E. Shimoni, "Development of functional bread containing nanoencapsulated omega-3 fatty acids," Journal of Food Engineering, vol. 105, no. 4, pp. 585-591, 2011.

[129] L. Rivas-Jimenez, K. Ramírez-Ortiz, A. F. González-Córdova, B. Vallejo-Cordoba, H. S. Garcia, and A. Hernandez-Mendoza, "Evaluation of acrylamide-removing properties of two _Lactobacillus_strains under simulated gastrointestinal conditions using a dynamic system," Microbiological Research, vol. 190, pp. 19-26, 2016. 